\title{
Genome-wide transcriptional adaptation to salt stress in Populus
}

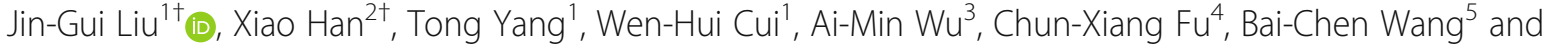 \\ Li-Jun Liu ${ }^{1 *}$
}

\begin{abstract}
Background: Adaptation to abiotic stresses is crucial for the survival of perennial plants in a natural environment. However, very little is known about the underlying mechanisms. Here, we adopted a liquid culture system to investigate plant adaptation to repeated salt stress in Populus trees.

Results: We first evaluated phenotypic responses and found that plants exhibit better stress tolerance after pretreatment of salt stress. Time-course RNA sequencing (RNA-seq) was then performed to profile changes in gene expression over $12 \mathrm{~h}$ of salt treatments. Analysis of differentially expressed genes (DEGs) indicated that significant transcriptional reprogramming and adaptation to repeated salt treatment occurred. Clustering analysis identified two modules of co-expressed genes that were potentially critical for repeated salt stress adaptation, and one key module for salt stress response in general. Gene Ontology (GO) enrichment analysis identified pathways including hormone signaling, cell wall biosynthesis and modification, negative regulation of growth, and epigenetic regulation to be highly enriched in these gene modules.

Conclusions: This study illustrates phenotypic and transcriptional adaptation of Populus trees to salt stress, revealing novel gene modules which are potentially critical for responding and adapting to salt stress.
\end{abstract}

Keywords: Abiotic stress, Adaptation, Perennial plants, Populus, Gene module

\section{Background}

Adaptation to various abiotic stresses is critical for the survival and biomass accumulation of sessile plants and is particularly true for perennial tree species due to their relatively long-life cycle. Populus, a model tree species due to the availability of a near complete set of experimental resources such as easy propagation, transformation methods, and abundance of genetic and genomic materials $[1,2]$, provides an ideal system to uncover how perennial trees adapt to abiotic stresses.

Recent studies in Arabidopsis thaliana and other model plants show that plants experiencing sub-lethal abiotic stress may memorize that stress at physiological and transcriptional levels to promote better performance when they encounter the same stress again [3-8]. For

\footnotetext{
* Correspondence: lijunliu@sdau.edu.cn

${ }^{\dagger}$ Jin-Gui Liu and Xiao Han contributed equally to this work.

${ }^{1}$ State Forestry and Grassland Administration Key Laboratory of Silviculture in downstream areas of the Yellow River, College of Forestry, Shandong

Agriculture University, Taian 271018, Shandong, China

Full list of author information is available at the end of the article
}

example, Arabidopsis and maize plants that have experienced one or more cycles of dehydration stress and watered recovery exhibit greater ability to retain leaf relative water content (RWC) compared to plants that have no experience of dehydration [9-11]. At the transcriptional level, stress response genes can be divided into two types based on their responsiveness to successive stress: 'memory genes' that show significantly different levels of up- or down-regulation in subsequent stress than the previous one, and 'non-memory genes' that show similar responses to each stress [12]. Comparative studies between Arabidopsis, maize, and switchgrass found that there are conserved dehydration memory genes but also remarkable differences in the total number and homologs of dehydration memory genes $[10,13]$, suggesting the existence of both evolutionarily conserved and species-specific mechanisms regulating plant responses to repeated abiotic stresses.

Transcriptional regulation is dynamic, and different types of genes usually respond to perturbations with different kinetics and patterns. Thus, it would be much 
more informative to profile plant transcriptional responses to abiotic stress with multiple time points of gene expression data rather than with a single time point [14-16]. The increasing capacity of high-throughput sequencing makes it feasible to characterize whole genome transcriptional dynamics with time-series RNA-seq experiments. Coupled with computational analysis, it is possible to identify key gene modules, hub genes or infer the hierarchical structure of the regulatory network using this kind of time-series expression data [16-23], and provide a better overview of how underlying biological processes are regulated.

High salinity, usually presented by accumulation of $\mathrm{NaCl}$ in soil, causes osmotic and ionic stresses, and is one of the most widely spread abiotic stresses that limit plant growth and distribution [24, 25]. Therefore, it is practically important to investigate the mechanisms of how plants adapt to salt stress. In this study, we established a precisely controlled liquid culture-based experimental procedure to investigate plant adaptation to salt stress in Populus. We first evaluated the phenotypic responses to salt stress and then performed time-course RNA-seq to characterize transcriptome dynamics during salt treatments. Our results showed that Populus plants displayed quick adaptation to salt stress phenotypically and transcriptionally. Key gene modules were identified through co-expression analysis, and the biological relevance of these gene modules were analyzed.

\section{Results}

Phenotypic adaptation to salt stress in Populus

In order to study plant adaptation to salt stress, we adopted the liquid culture system of Populus that allows precisely controlled $\mathrm{NaCl}$ treatments. We set up two groups of experiments: for the first group, we used $200 \mathrm{mM} \mathrm{NaCl}$ to do a high salt treatment directly; for the second group, we used $100 \mathrm{mM} \mathrm{NaCl}$ to do 1 day low salt treatment, then followed by 3 days of recovery culture, and finally high salt treatment with $200 \mathrm{mM} \mathrm{NaCl}$. In the first group, plants quickly showed a significantly severe stress phenotype, with strong shoot apical bend and leaves dropping. By contrast, in the second group, plants treated with low salt acted similar to the control plants, indistinguishable in phenotype to the control plants after 3 days of recovery and showed a mild response following $200 \mathrm{mM} \mathrm{NaCl}$ salt treatment (Fig. 1a). Time-course analysis further supported improved plant tolerance to $\mathrm{NaCl}$ treatment in the second group: plants responded to $200 \mathrm{mM} \mathrm{NaCl}$ treatment after $0.5 \mathrm{~h}$ and started to recover after $6 \mathrm{~h}$ while plants directly treated with $200 \mathrm{mM} \mathrm{NaCl}$ showed a much stronger

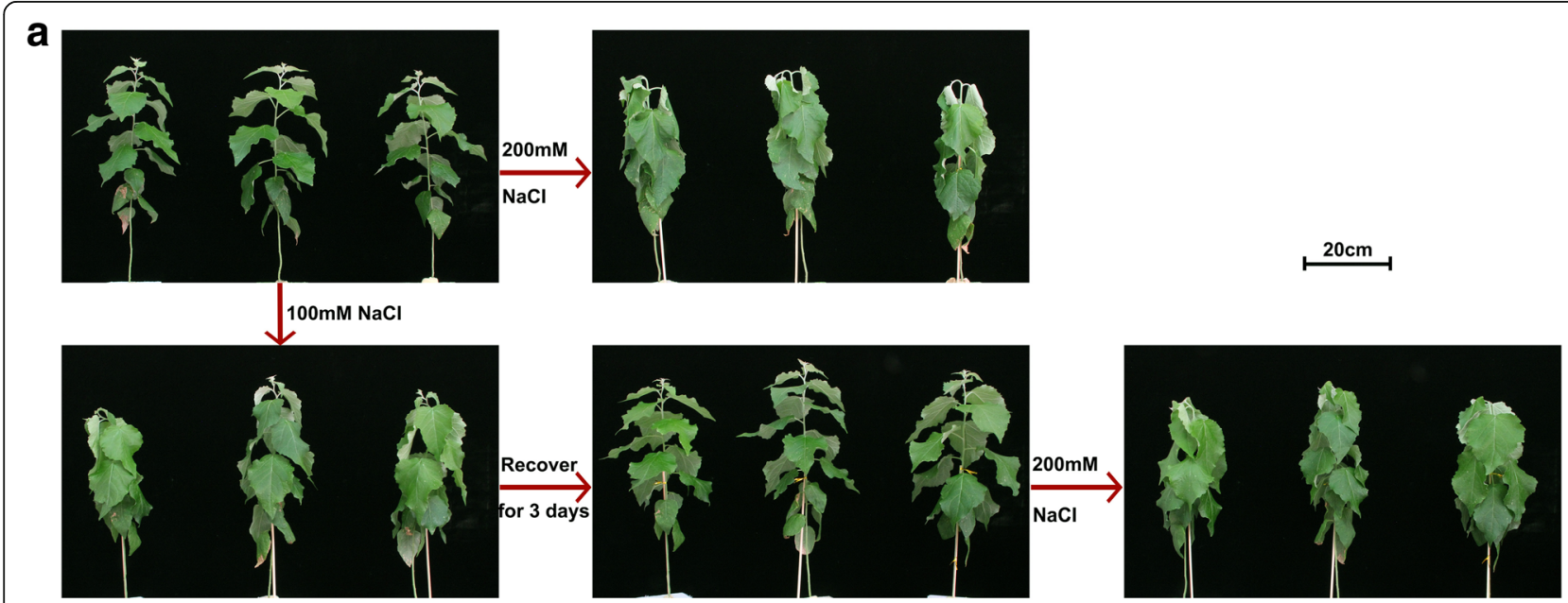

b

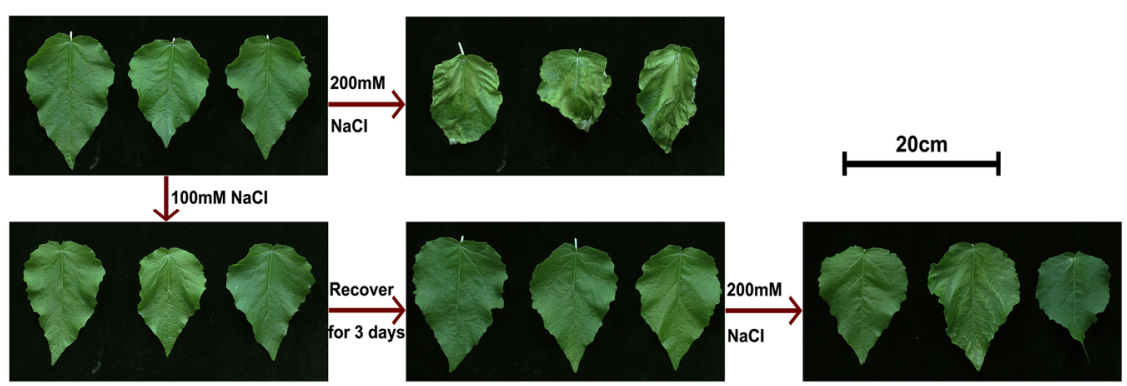

Fig. 1 Plant phenotypic responses during repeated $\mathrm{NaCl}$ treatments in Populus. a Whole plants responses to salt stress. Photos were taken $1 \mathrm{~h}$ after each $\mathrm{NaCl}$ treatment. Scale bar, $20 \mathrm{~cm}$. b Leaf phenotype during salt stress. Photos were taken $24 \mathrm{~h}$ after each NaCl treatment. Scale bar, $20 \mathrm{~cm}$ 
phenotype after $0.5 \mathrm{~h}$ and started to recover after $12 \mathrm{~h}$ (Additional file 1: Figure S1). Detailed inspection of the leaf phenotype showed consistent results with whole plant responses (Fig. 1b), with severe leaf damage in the first group, and mild damage in the second group. Overall, these results indicated that Populus plants could physiologically adapt to salt stress quickly after a pre-treatment.

\section{RNA-seq reveals massive transcriptional reprogramming in repeated salt stress}

We next performed RNA-seq to profile the dynamic changes of genome-wide transcript abundance during repeated salt treatments (Methods). We first treated the plants with $100 \mathrm{mM} \mathrm{NaCl}$ for 1 day, followed by 3 days of recovery culture, and then repeated $100 \mathrm{mM} \mathrm{NaCl}$ treatment again. Samples were collected after $0 \mathrm{~h}$ (control samples, designated as CK1 and CK2, respectively), $1 \mathrm{~h}, 3 \mathrm{~h}, 6$ $\mathrm{h}$, and $12 \mathrm{~h}$ (designated as T1H1, T1H3, T1H6, T1H12, T2H1, T2H3, T2H6, and T2H12, respectively) of each salt treatment (Fig. 2a). Notably, for RNA-seq sample preparation, we used $100 \mathrm{mM} \mathrm{NaCl}$ for both salt treatments to avoid the influence of different $\mathrm{NaCl}$ concentrations on transcription, and all time points for each treatment were collected within $2 \mathrm{~h}$ to minimize the influences of circadian rhythms or other environmental factors. High quality total RNAs were isolated and submitted for RNA-seq library construction and sequencing. At least 45-76 million $150 \mathrm{bp}$ paired-end clean reads were obtained for each library (Additional file 7: Table S1).

To identify differentially expressed genes (DEGs) during each salt treatment, we performed pair-wise edgeR analysis between individual time point and the corresponding control samples. The number of DEGs changed dramatically along the time-course of each treatment
(Additional file 8: Table S2; Additional file 9: Table S3). Moreover, DEGs at the same time point of the first treatment (T1) and the second treatment (T2) were dramatically different. For example, there were 2171 DEGs in the T1H1/CK1 group whereas there were only 179 in the T2H1/CK2 group. Overlapping studies found that there were $145,836,473$, and 1551 common genes for each time point (Fig. 2b), which account for $81,41,54$, and $73 \%$ of the smaller dataset, respectively. Overall, the differences in the total number of DEGs and the low overlapping rates indicate that massive transcriptional reprogramming during repeated salt treatments occurred. Notably, there were 1051 DEGs between CK1 and CK2, with 649 up-regulated and 402 down-regulated DEGs. GO function annotation showed that 43 out of 1051 DEGs were involved in response to salt stress. Among those 43 DEGs, 19 were up-regulated, including membrane transporter proteins and MYB transcription factors; 24 were down-regulated, including tonoplast intrinsic protein TIP1, drought-induced protein Di19, gibberellin-regulated protein GASA14, and calcium signaling proteins CDPK and GAP1 (Additional file 9: Table S3).

\section{Co-expression analysis identifies key gene modules in response to repeated salt stress}

To better understand the correlation of gene expression between time-course treatments, weighted gene correlation network analysis (WGCNA) was performed. In total, 10 co-expressed gene modules, which showed different expression curves and peaks during $\mathrm{NaCl}$ treatments, were identified (Fig. 3a; Additional file 2: Figure S2; Additional file 10: Table S4). Module size ranged from 692 to 8341 genes, with the green module containing a moderate amount (2071 genes), while the blue (7173

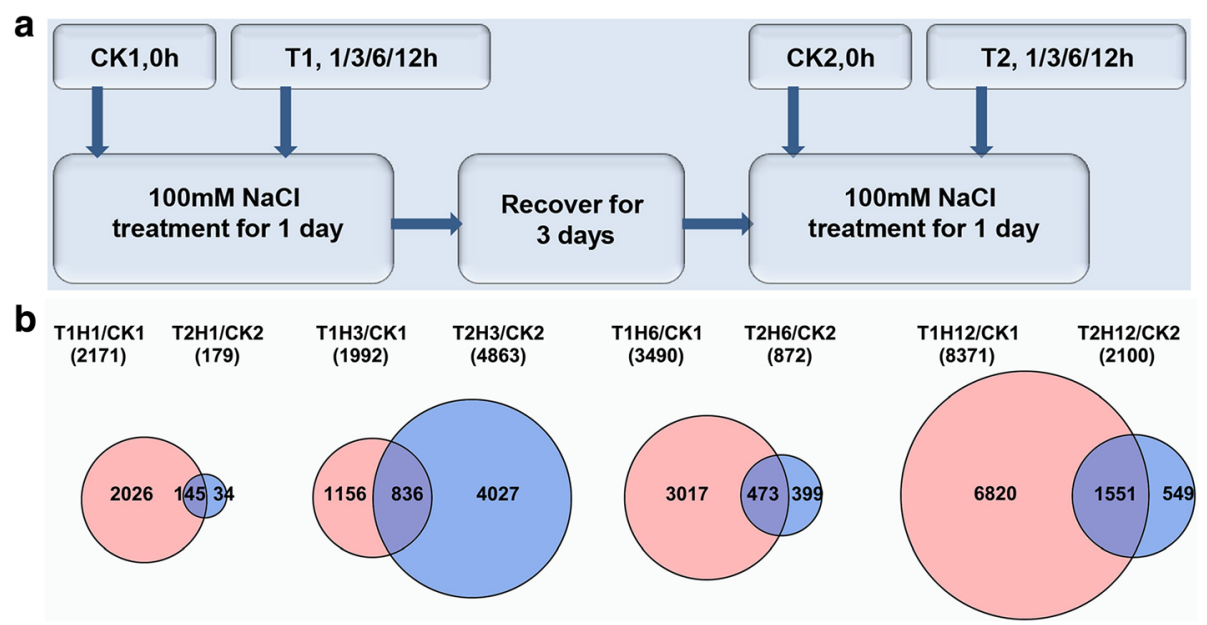

Fig. 2 Overview of the RNA-seq data. a Workflow for RNA-seq sample preparation. $\mathbf{b}$ Venn diagrams show overlap of differentially expressed genes (DEGs) between the same time point of repeated $\mathrm{NaCl}$ treatment. $\mathrm{T} 1$ : the first salt treatment; T2: the second salt treatment after 3 days recovery following the first salt treatment; $\mathrm{H} 1 / \mathrm{H} 3 / \mathrm{H} 6 / \mathrm{H} 12: 1 / 3 / 6 / 12 \mathrm{~h}$ of salt treatment 


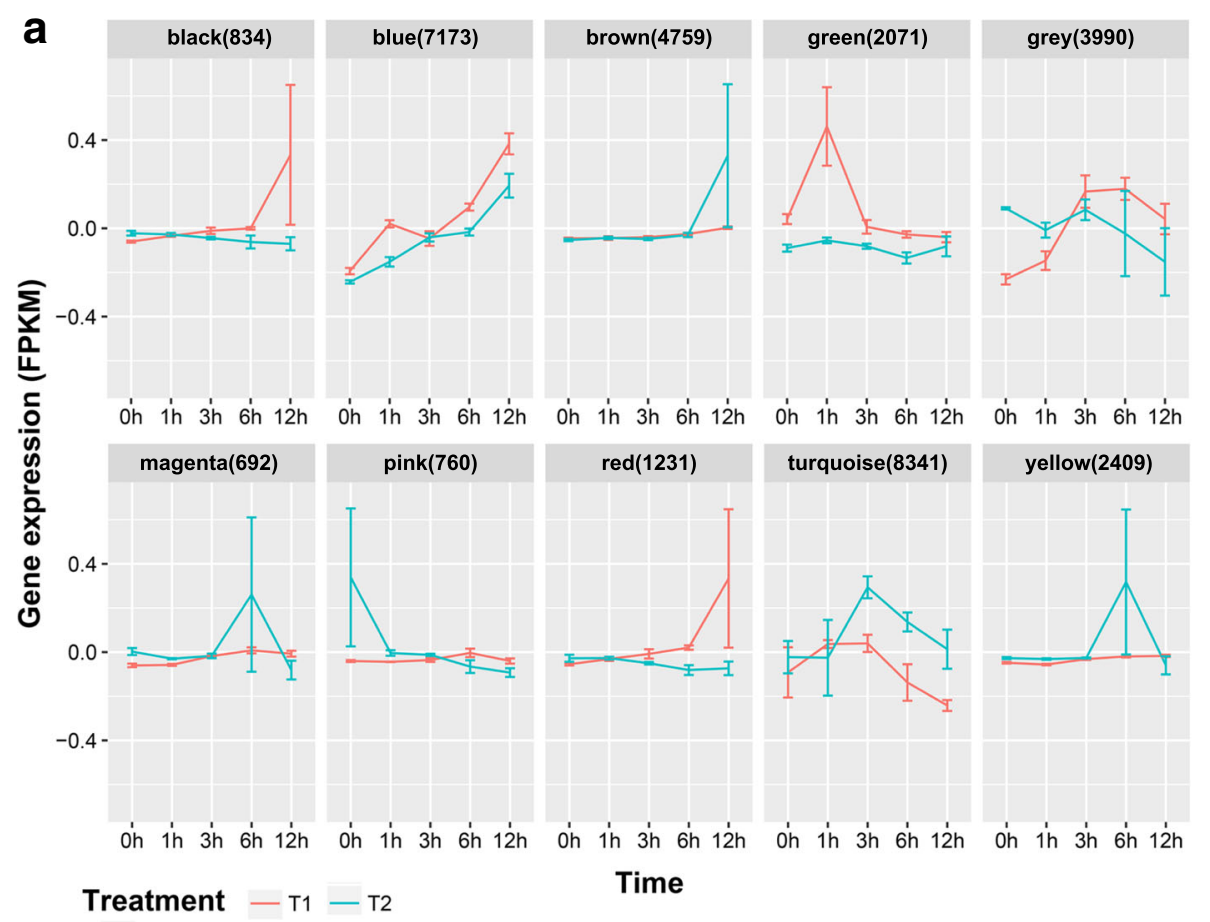

b Module-Trait relationships

\begin{tabular}{r|cc|} 
turquoise & 0.43 & -0.093 \\
& $(0.02)$ & $(0.6)$ \\
yellow & 0.19 & 0.15 \\
& $(0.3)$ & $(0.4)$ \\
magenta & 0.15 & 0.11 \\
& $(0.4)$ & $(0.5)$ \\
grey & -0.011 & 0.14 \\
pink & $(1)$ & $(0.4)$ \\
& 0.18 & -0.34 \\
brown & $(0.3)$ & $(0.06)$ \\
& 0.17 & 0.35 \\
green & $(0.4)$ & $(0.06)$ \\
& -0.48 & -0.28 \\
red & $(0.007)$ & $(0.1)$ \\
black & -0.28 & 0.26 \\
blue & $(0.1)$ & $(0.2)$ \\
& -0.25 & 0.27 \\
& $(0.2)$ & $(0.2)$ \\
& -0.28 & 0.87 \\
& $(0.1)$ & $(6 e-10)$ \\
& Treatment & Time
\end{tabular}

Fig. 3 Co-expressed gene modules identified by Weighted Gene Co-expression Network Analysis (WGCNA). a Module dynamic eigengene expression in response to $\mathrm{NaCl}$ treatments $(\mathrm{T} 1, \mathrm{~T} 2)$. The numbers in parentheses represent the number of genes in the module. $\mathbf{b}$ Correlation of individual gene module with Treatment $(T 1, T 2)$ and Time $(0 \mathrm{~h}, 1 \mathrm{~h}, 3 \mathrm{~h}, 6 \mathrm{~h}, 12 \mathrm{~h})$. The number stand for correlation value and related $P$ value (in parentheses) between the module and "Treatment" or "Time". $P$ value $<0.05$ was the statistical significance threshold

genes) and turquoise (8341 genes) modules contained the largest number of genes (these three modules showed significant correlation with salt stress response or adaptation as discussed later) (Table 1).

Gene expression profile was visualized with eigengene values (the first principal component of transcript profiles) for each module and showed distinct co-expression patterns across modules (Fig. 3a): the blue module increased along the time-course and showed similar changes between the first and the second treatment, the green module showed a significant peak at $1 \mathrm{~h}$ of the first treatment compared to the second treatment, and the turquoise module showed a significant peak at $3 \mathrm{~h}$ of the second treatment compared to the first treatment, the other seven modules did not have significant changes across the time-course. Consistently, ModuleTrait relationships showed that the green and turquoise modules highly correlated with "Treatment" (T1 and 
Table 1 Summary of all co-expression gene modules

\begin{tabular}{lllll}
\hline Modules & Gene number $^{\mathrm{a}}$ & TF number $^{\mathrm{b}}$ & \% of TF & $P^{\mathrm{C}}$-value $^{\mathrm{d}}$ \\
\hline Magenta & 692 & 64 & 9.25 & 0.000119395 \\
Pink & 760 & 29 & 3.82 & 0.002390257 \\
Black & 834 & 52 & 6.24 & 0.05321326 \\
Red & 1231 & 58 & 4.71 & 0.009453082 \\
Green & 2071 & 196 & 9.46 & $1.66995 \mathrm{E}-11$ \\
Yellow & 2409 & 182 & 7.56 & $9.83444 \mathrm{E}-05$ \\
Grey & 3990 & 270 & 6.77 & 0.001601634 \\
Brown & 4759 & 345 & 7.25 & $6.59708 \mathrm{E}-06$ \\
Blue & 7173 & 517 & 7.21 & $7.64648 \mathrm{E}-08$ \\
Turquoise & 8341 & 376 & 4.51 & $7.21849 \mathrm{E}-11$ \\
\hline
\end{tabular}

TF Transcription Factor

${ }^{a}$ gene numbers in each module, ${ }^{\mathrm{b}}$ TF numbers in each module, ${ }^{\mathrm{c}_{\mathrm{C}}} \%$ of TF genes in each module, ${ }^{d} P$-value was the statistical result of number of TF gene in the corresponding gene module and was derived from HYMGEOMDIST test. \% of TFs in Populus genome is $5.91 \%$

$\mathrm{T} 2$ ), whereas the blue module significantly correlated with "Time" ( $1 \mathrm{~h}, 3 \mathrm{~h}, 6 \mathrm{~h}$, and $12 \mathrm{~h}$ ) (Fig. 3b). Other seven modules showed relatively low correlation to any variable. These results indicated that the green and turquoise modules may be critical for adaptation to repeated salt stress, whereas the blue module appears to be essential for each salt stress response. Therefore, we focused on analyzing the green, turquoise, and blue modules.

The salt overly sensitive (SOS) pathway is essential for salt tolerance in plants [26]. There are three homologs of SOS1, two of SOS2, and five of SOS3 in Populus genome. We checked our co-expression analysis and found that two homologs of SOS1 were classified into turquoise module, two of SOS2 were classified into blue module, and one of the SOS3 was in green module and one was in turquoise module (Additional file 10: Table S4).

Transcription factors (TFs) are important regulators in plant development and response to stress [27-33]. Therefore, we investigated the distribution of TF genes in these three gene modules. Compared to the whole genome, the green and blue modules contained a significantly higher percentage of TF, whereas the turquoise module contained a significantly lower percentage of TF (Table 1; Additional file 11: Table S5). Additional file 12: Table S6 shows a summary of individual TF families in the green, turquoise, and blue modules. Statistical analysis found that the green module was significantly enriched in the MYB/MYB-related, ERF, bHLH, and HD-ZIP families of TFs, whereas the blue module was significantly enriched in the NAC, bZIP, WRKY, C3H, B3 and HSF families of TFs. These results provide valuable information for identifying key regulators that underly plant responses to salt stress in general, but more importantly, adaptation to salt stress.

\section{Gene ontology enrichment analysis of the key gene modules}

To further explore the functional significance of the key gene modules, we performed gene ontology (GO) enrichment analysis to identify significantly enriched biological pathway (BP), molecular function (MF), and cellular component (CC) GO terms of each gene module. In total, 399, 154, and 681 enriched BP GO terms were identified from the blue, green, and turquoise modules, respectively (Additional file 13: Table S7).

Plant hormones are important regulators for abiotic stress responses. In this study, we found enriched GO terms for all classical plant hormone pathways in the selected gene modules (Table 2). Interestingly, genes functioning in auxin polar transport and signaling are mainly enriched in the green and turquoise modules, whereas genes functioning in abscisic acid (ABA) and salicylic acid (SA) signaling pathways are only enriched in the blue module. Jasmonic acid (JA) signaling pathways are highly enriched in the blue module. Genes functioning in responses to plant hormone gibberellins (GA), brassinosteroid (BR), and ethylene (ET) are also enriched in the green module. These results indicate that plant hormones, especially auxin may be critical for plant adaptation to repeated salt stress while ABA, SA, and JA are essential for plant responses but not sufficient for plant adaptation to each salt stress.

Detailed analysis confirmed that each module has specific enriched GO terms. For example, the green module showed enrichment in negative regulation of growth (Additional file 3: Figure S3; Additional file 13: Table S7); the turquoise module is enriched in GO terms involved in RNA transport and catabolic, protein modification and transport, and meristem development (Additional file 4: Figure S4; Additional file 13: Table S7); and the blue module is enriched in regulation of mitotic cell cycle, protein dephosphorylation, programmed cell death, and response to abiotic stress (Additional file 5: Figure S5; Additional file 13: Table S7). Remarkably, cell wall related GO terms are highly enriched in green module, such as plant-type cell wall biogenesis, plant-type cell wall modification, cell wall loosening, and lignin/pectin metabolic or catabolic process (Table 2); and the turquoise module is significantly enriched in epigenetic modification pathways such as histone methylation, DNA methylation, and chromatin organization (Additional file 4: Figure S4; Additional file 13: Table S7).

\section{Verification of gene expression profile of the green, turquoise and blue module}

To validate the gene expression profiles derived from RNA-seq analysis, we randomly selected six genes from green, turquoise, and blue module with relatively higher module membership value (MM value) and expression 
Table 2 Enrichment of plant hormone and cell wall related gene ontology (GO) categories in each gene module

\begin{tabular}{|c|c|c|c|}
\hline GOBPID & $P$-value & Module & Term \\
\hline \multicolumn{4}{|l|}{ Auxin } \\
\hline GO:0009734 & $1.38 \mathrm{E}-07$ & green & auxin-activated signaling pathway \\
\hline GO:0009733 & $3.62 \mathrm{E}-07$ & green & response to auxin \\
\hline GO:0071365 & $4.58 \mathrm{E}-07$ & green & cellular response to auxin stimulus \\
\hline GO:0060918 & 0.001810948 & green & auxin transport \\
\hline GO:0009926 & 0.002255868 & green & auxin polar transport \\
\hline GO:0009926 & 0.006351523 & pink & auxin polar transport \\
\hline GO:0060918 & 0.008487031 & pink & auxin transport \\
\hline GO:0071365 & 0.000658331 & turquoise & cellular response to auxin stimulus \\
\hline GO:0009734 & 0.003241714 & turquoise & auxin-activated signaling pathway \\
\hline GO:0010540 & 0.00491535 & turquoise & basipetal auxin transport \\
\hline GO:0009733 & 0.00886687 & turquoise & response to auxin \\
\hline \multicolumn{4}{|l|}{ Gibberellins } \\
\hline GO:0010371 & 0.006713667 & brown & $\begin{array}{l}\text { regulation of gibberellin biosynthetic } \\
\text { process }\end{array}$ \\
\hline GO:0009739 & 0.000443904 & green & response to gibberellin \\
\hline \multicolumn{4}{|l|}{ Cytokinin } \\
\hline GO:0080037 & 0.001227355 & blue & $\begin{array}{l}\text { negative regulation of cytokinin-activated } \\
\text { signaling pathway }\end{array}$ \\
\hline GO:0009735 & 0.000982346 & turquoise & response to cytokinin \\
\hline \multicolumn{4}{|l|}{ Brassinosteroid } \\
\hline GO:0009741 & 0.00057973 & green & response to brassinosteroid \\
\hline \multicolumn{4}{|l|}{ Ethylene } \\
\hline GO:0009723 & 4.79E-05 & black & response to ethylene \\
\hline GO:0009873 & 0.000328341 & black & ethylene-activated signaling pathway \\
\hline GO:0071369 & 0.000505744 & black & cellular response to ethylene stimulus \\
\hline GO:0071369 & 4.95E-05 & green & cellular response to ethylene stimulus \\
\hline GO:0009873 & 0.000260229 & green & ethylene-activated signaling pathway \\
\hline GO:0009723 & 0.000263073 & green & response to ethylene \\
\hline GO:0010105 & $3.66 \mathrm{E}-07$ & red & $\begin{array}{l}\text { negative regulation of ethylene-activated } \\
\text { signaling pathway }\end{array}$ \\
\hline GO:0010104 & $6.91 \mathrm{E}-06$ & red & $\begin{array}{l}\text { regulation of ethylene-activated signaling } \\
\text { pathway }\end{array}$ \\
\hline \multicolumn{4}{|l|}{ Jasmonic acid } \\
\hline GO:0009753 & 0.000493563 & blue & response to jasmonic acid \\
\hline GO:2000022 & 0.001852248 & blue & $\begin{array}{l}\text { regulation of jasmonic acid mediated } \\
\text { signaling pathway }\end{array}$ \\
\hline GO:0009867 & 0.002393932 & blue & jasmonic acid mediated signaling pathway \\
\hline GO:0071395 & 0.00350308 & blue & cellular response to jasmonic acid stimulus \\
\hline GO:0009694 & 0.000172051 & green & jasmonic acid metabolic process \\
\hline GO:0009753 & 0.001153948 & green & response to jasmonic acid \\
\hline \multicolumn{4}{|l|}{ Abscisic acid } \\
\hline GO:0009737 & $4.22 \mathrm{E}-06$ & blue & response to abscisic acid \\
\hline GO:0009738 & 0.00056742 & blue & abscisic acid-activated signaling pathway \\
\hline GO:0071215 & 0.003692747 & blue & cellular response to abscisic acid stimulus \\
\hline
\end{tabular}

Salicylic acid 
Table 2 Enrichment of plant hormone and cell wall related gene ontology (GO) categories in each gene module (Continued)

\begin{tabular}{|c|c|c|c|}
\hline GOBPID & $P$-value & Module & Term \\
\hline GO:0009862 & $6.20 \mathrm{E}-07$ & blue & $\begin{array}{l}\text { systemic acquired resistance, salicylic acid } \\
\text { mediated signaling pathway }\end{array}$ \\
\hline GO:0010337 & 0.001421978 & blue & regulation of salicylic acid metabolic process \\
\hline GO:0009863 & 0.001776784 & blue & salicylic acid mediated signaling pathway \\
\hline GO:0071446 & 0.002641471 & blue & cellular response to salicylic acid stimulus \\
\hline GO:0009751 & 0.004901824 & blue & response to salicylic acid \\
\hline GO:0046244 & 0.005445888 & blue & salicylic acid catabolic process \\
\hline \multicolumn{4}{|l|}{ Cell wall } \\
\hline GO:0044036 & 0.00034442 & blue & cell wall macromolecule metabolic process \\
\hline GO:0010383 & 0.001016966 & blue & cell wall polysaccharide metabolic process \\
\hline GO:0071554 & $1.66 \mathrm{E}-07$ & green & cell wall organization or biogenesis \\
\hline GO:0042546 & $2.02 \mathrm{E}-06$ & green & cell wall biogenesis \\
\hline GO:0009834 & 5.04E-06 & green & plant-type secondary cell wall biogenesis \\
\hline GO:0071669 & $8.26 \mathrm{E}-06$ & green & plant-type cell wall organization or biogenesis \\
\hline GO:0009832 & 0.000110576 & green & plant-type cell wall biogenesis \\
\hline GO:1901347 & 0.000132263 & green & $\begin{array}{l}\text { negative regulation of secondary cell wall } \\
\text { biogenesis }\end{array}$ \\
\hline GO:1903339 & 0.000132263 & green & $\begin{array}{l}\text { negative regulation of cell wall organization } \\
\text { or biogenesis }\end{array}$ \\
\hline GO:0042545 & 0.000240471 & green & cell wall modification \\
\hline GO:0009827 & 0.000539041 & green & plant-type cell wall modification \\
\hline GO:0071555 & 0.002039367 & green & cell wall organization \\
\hline GO:0009664 & 0.003032875 & green & plant-type cell wall organization \\
\hline GO:0009828 & 0.006460053 & green & plant-type cell wall loosening \\
\hline GO:0016998 & 0.004935135 & pink & cell wall macromolecule catabolic process \\
\hline GO:0009664 & 0.008475018 & red & plant-type cell wall organization \\
\hline GO:0071555 & 0.008547578 & red & cell wall organization \\
\hline GO:0009833 & 0.000480169 & turquoise & plant-type primary cell wall biogenesis \\
\hline GO:2000652 & 0.002143591 & yellow & regulation of secondary cell wall biogenesis \\
\hline GO:0009809 & 2.82E-07 & green & lignin biosynthetic process \\
\hline GO:0009808 & 4.08E-07 & green & lignin metabolic process \\
\hline GO:0046274 & 1.47E-05 & green & lignin catabolic process \\
\hline GO:0010410 & 0.008590021 & blue & hemicellulose metabolic process \\
\hline GO:0045490 & 0.000254293 & green & pectin catabolic process \\
\hline GO:0045488 & 0.001028476 & green & pectin metabolic process \\
\hline
\end{tabular}

level for quantitative PCR (qPCR) test. Similar expression patterns were found for all selected genes (Fig. 4; Additional file 6: Figure S6), suggesting that our results of co-expression analysis with RNA-seq data are reliable for analyzing gene expression in response to repeated salt stress in Populus.

\section{Co-expression network exploration}

Co-expression network analysis shows the correlation of genes based on their expression patterns, showing possible causality in expression changes of co-expressed genes under certain experimental conditions. WOX4CLE41 signaling pathway has been shown as the central regulator of cambium cell fate controlling secondary growth rate in Populus [34, 35], therefore, we used the WOX $4 b$ and CLE41a genes from green module as an example to further explore the co-expression network derived from this study. Top 20 co-expressed genes were displayed for each gene (Fig. 5; Additional file 14: Table S8). In WOX $4 b$ co-expressed genes, MIOX4, bHLH TF, two peroxidases, several kinds of transporter genes, and cell wall biogenesis and lignification related genes such 


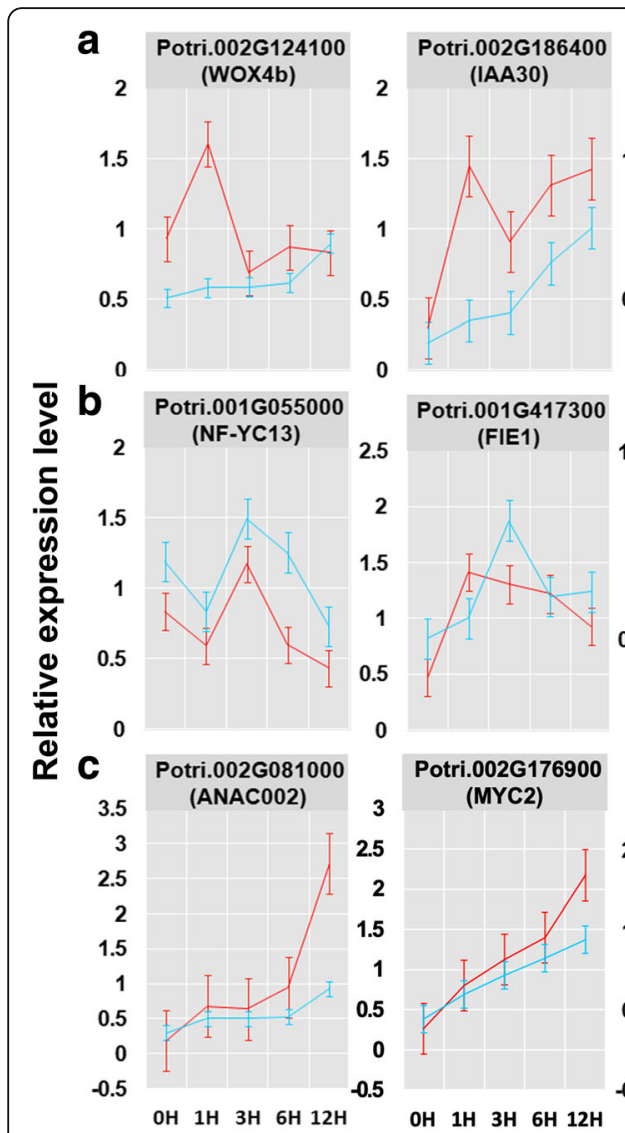

Treatment

$-\mathrm{T} 1-\mathrm{T} 2$

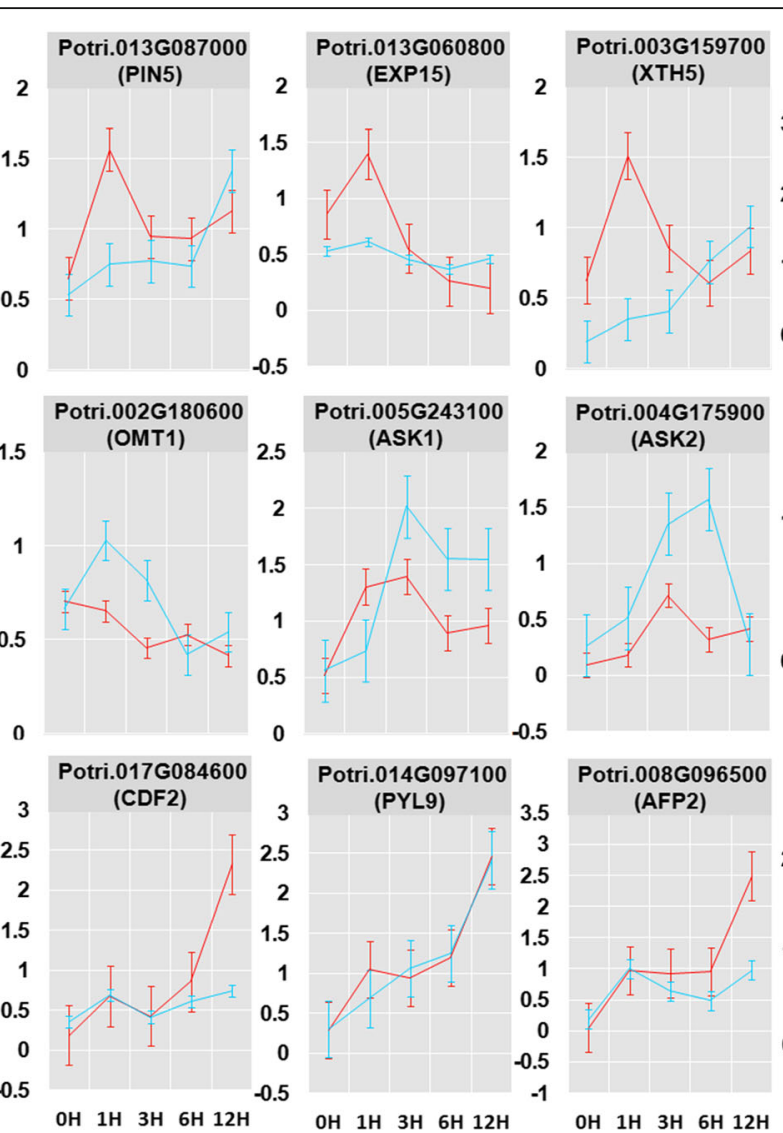

Time

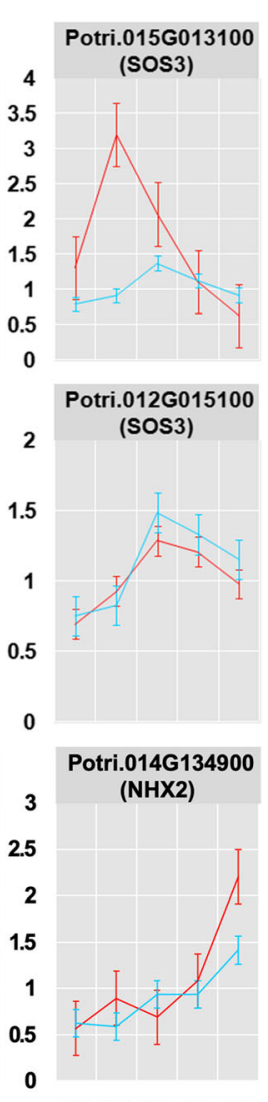

OH $1 \mathrm{H} 3 \mathrm{H} \quad 6 \mathrm{H} 12 \mathrm{H}$

Fig. 4 Verification of the expression profile of representative genes from green (a), turquoise (b), and blue (c) module by quantitative real-time PCR. Relative gene expression level was calculated using actin as the internal control. The results were means \pm SE with three biological replicates for each sample

as pectin lyase-like superfamily protein, plant invertase/ pectin methylesterase inhibitor superfamily, and xyloglucan endoxyloglucan transferase XTH6 were found. Among CLE41a co-expressed genes, actin depolymerizing factor $A D F 5, L O L 1, M L P 28$, gene encoding peptidase C15, protein kinase, and notably, WOX4b were found. Moreover, CLE41a was reported to be regulated by auxin and there was one SAUR-like auxin-responsive gene and IAA16 among the CLE41a top 20 co-expressed genes. These co-expressed genes are possibly important for the regulation of plant growth during salt stress.

\section{Discussion}

Transcriptional regulation has been shown to play important roles in plant response and adaptation to abiotic stresses [5, 36, 37]. Therefore, identifying key transcriptional regulatory genes and signaling pathways that participate in the regulation of plant response to abiotic stresses is critical for genetic or biotechnological improvement of plant survival rate and biomass production. Recently, there have been several comprehensive studies on plant adaptation to abiotic stresses. However, our knowledge of how perennial trees respond to repeated abiotic stress is still limited. In this study, we used hybrid poplar clone $84 \mathrm{~K}$ (Populus alba X Populus glandulosa) as a model system to investigate plant responses to repeated salt stress, and demonstrated the adaption of perennial trees to abiotic stresses.

\section{Populus plant could adapt to salt stress quickly at both physiological and transcriptional levels}

We developed a liquid-culture system, which enabled us to precisely control the $\mathrm{NaCl}$ dosage and time of treatments, to investigate how Populus plant's responds to repeated salt stress. Observation of whole plant responses and leaf phenotype to repeated salt stress demonstrated that plants experiencing 1 day of low $\mathrm{NaCl}$ pre-treatment followed by 3 days recovery perform much better in high $\mathrm{NaCl}$ treatment than plants treated directly with high $\mathrm{NaCl}$ (Fig. 1). This suggests Populus could adapt to salt stress quickly at the physiological level.

We also performed time-course RNA-seq to profile transcriptional dynamics in response to $\mathrm{NaCl}$ treatments, 


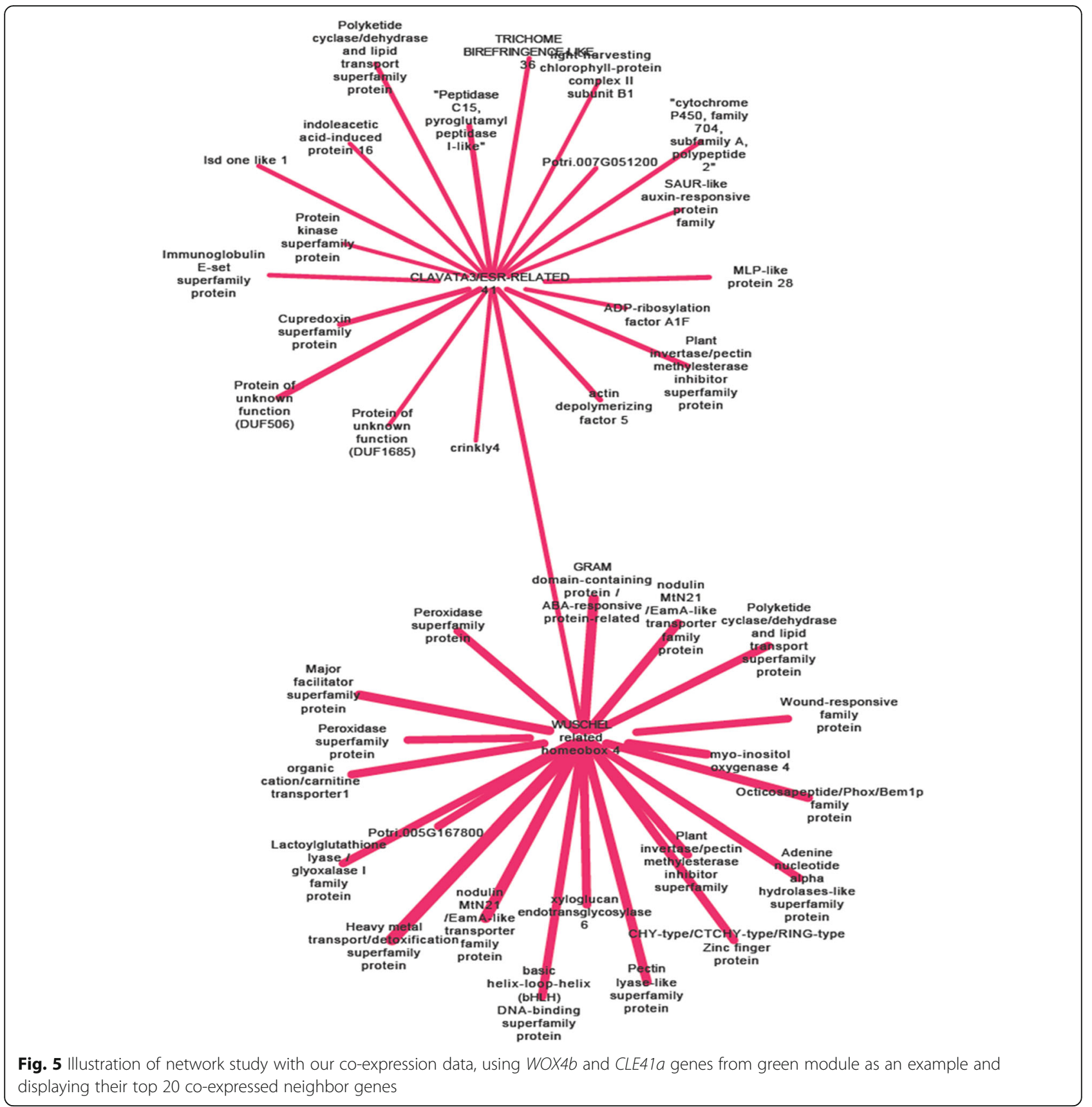

which provide a better resolution than single time point RNA-seq data. The total number of DEGs over the timecourse and DEGs pair-wise overlapping study revealed that there were dynamic and massive transcriptional reprogramming in successive salt treatments (Fig. 2; Additional file 8: Table S2). Notably, there were less DEGs in T2 at all time points except $3 \mathrm{~h}$, in which T2H3/CK2 has more DEGs than T1H3/CK1. Furthermore, the turquoise module from our co-expression analysis, which was the largest module and contain 8341 genes, has a relatively higher expression peak in
$\mathrm{T} 2 \mathrm{H} 3$ than T1H3. The turquoise module was enriched in GO categories such as auxin polar transport and signaling, RNA transport and catabolic, protein modification and transport, meristem development, and epigenetic modification pathways that were possibly important for salt adaptation. Therefore, we thought this could be reflective of plant response to repeated salt stress. Another interesting point from DEG analysis was that, there were still over 1000 genes that showed significantly differential expression after 3 days recovery culture (Additional file 8: Table S2) even though plant phenotype returned to pre- 
treated status, suggesting that transcriptional regulation is more sensitive than physiological regulation and 3 days recovery culture is not enough to completely reverse the transcriptional changes. This phenomena is consistent with previous results reported by others that plants retains the transcriptional memory of abiotic stress for up to 5 days $[8,9]$. It would be interesting to investigate how their transcriptional levels are retained during the recovery period.

\section{Co-expression analysis identify putative gene modules critical for salt stress adaptation}

With this time-series RNA-seq data, gene co-expression analysis was performed using the WGCNA package and 10 modules were identified. Each module has different gene expression profiles along $\mathrm{NaCl}$ treatments. Based on the analysis of module-trait correlation we decided to focus on the green, turquoise, and blue modules which showed significantly high correlation to repeated "Treatment" or "Time" (Fig. 3). Overall, genes in the green module reached their expression peak at $1 \mathrm{~h}$ of the first treatment but not the second treatment, whereas genes in the turquoise module showed an expression peak at 3 $h$ of the second treatment but not the first treatment. This suggested that genes from these two modules could discriminate the first and repeated salt stresses and possibly lead to salt stress adaptation. On the other hand, expression levels of genes in the blue module increased along the time-course and showed similar patterns between the first and the second salt treatment, indicating that genes from this module are important for the plant response to salt stress in general.

Study of genome-wide TF distribution found that the green and blue modules contained significantly more TF genes whereas the turquoise module contained significantly less, indicating that the green and blue modules may act at a higher hierarchical level of transcriptional regulation that initiates a transcriptional signaling cascade to regulate downstream gene expression. The green module is significantly enriched in MYB/MYB-related, ERF, bHLH, and HD-ZIP families of TFs and the blue module is significantly enriched in NAC, bZIP, WRKY, $\mathrm{C} 3 \mathrm{H}, \mathrm{B} 3$ and HSF families of TFs. All of these TF families have been shown to be important regulators of abiotic stress responses [27, 28, 30-33, 38, 39]. However, whether they are participating in the regulation of stress adaptation still needs further investigation. This analysis provides putative candidate genes for genetic studies of plant transcriptional responses to abiotic stress for future studies.

Maintaining ion homeostasis is crucial for plant tolerance and adaptation to salt stress. The salt overly sensitive (SOS) pathway, including SOS1, SOS2, and SOS3, has been shown as a central player in sodium ion efflux under salt stress [40-42], and is conserved across different plant species such as Arabidopsis [26], rice [43], tomato [44], and poplar [45]. In our co-expression analysis, two homologs of SOS1 were classified into turquoise module, two of SOS2 were classified into blue module, one of SOS3 was in green module and one was in turquoise module (Fig. 4; Additional file 10: Table S4). The $\mathrm{H}^{+}$electrochemical gradient across membranes could drive the $\mathrm{Na}^{+}$compartmentalization into vacuoles or exclusion out cells, and is generated by $\mathrm{H}^{+}$pump such as $\mathrm{H}^{+}$-pyrophosphate VP1 [46]. Two VP1 homolog genes were belong to turquoise module in our co-expression analysis (Additional file 10: Table S4), one of which have been functionally characterized in poplar and could improve plant growth under salt stress [47]. Together, these results suggest that Populus tree may adapt to repeated salt stress through modifying ion sensing and transporting pathways.

\section{Functional analysis of the gene modules suggested plant hormones and epigenetic modifications are critical for Populus plant's adaptation to salt stress}

Plant hormones are important regulators of plant responses to abiotic stress and complex crosstalk occurs among the signaling pathways of different hormones for coordinating plant growth [29, 41, 48-52]. In general, $\mathrm{ABA}, \mathrm{SA}, \mathrm{JA}$, and ET are characterized as "stress hormones" which are responsible for a plants' quick response to biotic or abiotic stresses, whereas auxin, GA, BR, and cytokinin are recognized as "growth promoting hormones" which modify plant developmental processes in the longterm $[49,53]$. Interestingly, our GO enrichment analysis with co-expression gene modules suggested that plant hormones play important roles in Populus response and adaptation to repeated salt stress. Moreover, the above two types of plant hormones may function at different aspects of plant response and adaptation to abiotic stresses. For example, we found that the ABA signaling pathway was only enriched in the blue module, suggesting that $\mathrm{ABA}$ signaling is necessary for plant response but not sufficient for plant adaptation to repeated salt stress, which is consistent with previous reports $[9,54]$. JA and SA signaling pathways were also specifically enriched in the blue module. On the other hand, auxin, GA, and BR signaling or transport pathways were highly enriched in the green or turquoise modules, which indicated that these plant hormones may play critical roles in plant adaptation to salt stress through modulating the plant growth pattern in the long-term. There are also highly enriched GO terms referring to negative regulation of growth and cell wall biogenesis/modifications in the green module. It would be important to analyze how these plant hormones change and identify their crosstalk signaling pathways in the plant response and adaptation to abiotic stress, thus 
uncovering key signaling genes for improving plant growth during abiotic stresses.

Epigenetic regulation has been proposed as one of the mechanisms underlying transcriptional stress memory [37, 55-58]. For example, histone trimethylation markers H3K4me3 and H3K27me3 correlate to the target gene's transcriptional memory in dehydration stress $[9,59,60]$. Also, DNA methylation changes in particular regions of the Arabidopsis genome are responsible for hyperosmotic stress memory caused by salt treatments [61]. In our results, we found epigenetic pathways, such as histone methylation, histone ubiquitination, DNA methylation, and chromatin organization, were highly enriched in the turquoise module which correlated with "Treatment" and showed a peak expression level in T2H3 (Fig. 3). To further reveal the mechanisms of plant adaptation to abiotic stress, it would be important to investigate when do these epigenetic modifications establish, the effects of these epigenetic modification on the expression of target genes, and their dynamics during the recovery period.

\section{Conclusions}

In this study, we reported that Populus plants could adapt to salt stress quickly in both physiological and transcriptional levels. We also did time-series RNA-seq to profile the transcriptome dynamics during repeated salt treatments and showed that there was significant reprogramming at the transcriptional level. Our co-expression analysis with these time-series RNA-seq data identified 10 co-expressed gene modules, including two modules which were highly correlated to repeated salt stress and one module which was highly correlated to general salt stress response. Gene ontology (GO) analysis suggested that plant hormones regulating plant growth, particularly auxin signaling pathway, are possibly play critical roles in plant adaptation to repeated salt stress, and $\mathrm{ABA}$ signaling is critical for general response to salt stress. Cell wall biosynthesis/modification and epigenetic regulation are also suggested as important regulatory pathways for plant adaptation to salt stress. In summary, our results provided a framework for dissecting signaling pathways and identifying key regulatory genes for plant adaptation to salt stress in Populus.

\section{Methods}

\section{Plant cultivation and sample collection}

Hybrid poplar (Populus alba X Populus glandulosa) clone $84 \mathrm{~K}$, grown under $16 \mathrm{~h}$ light $/ 8 \mathrm{~h}$ dark photoperiod condition and at $25^{\circ} \mathrm{C}$, was used for all experiments. All plants were propagated in Shandong Agriculture University (Taian, Shandong, China). $84 \mathrm{~K}$ seedlings were subcultured in magenta boxes under controlled growth chamber, and then transferred to soil 1 month later, finally transferred to full Hoagland nutrient solution for another 3 weeks growth before $\mathrm{NaCl}$ treatments. Defoliated stems from apex to fourth internodes were collected and immediately frozen in liquid nitrogen for RNA extraction. Three biological replicates were collected for each sample, and three plants were combined for each biological replicate.

\section{RNA extraction and qPCR}

Samples collected from apex to 4th internode were ground to fine powder in liquid nitrogen. Total RNAs were extracted with CTAB method, treated with DNase (TaKaRa, 2270) and then purified with column from TaKaRa MiniBEST Plant RNA Extraction Kit (TaKaRa, 9769). The RNA purity and integrity were assessed by NanoDrop 2000 and Agilent 2100 Bioanalyzer. $0.5 \mu \mathrm{g}$ total RNA was used for cDNA synthesis using HiScript II Q Select RT SuperMix for qPCR (+gDNA wiper) (Vazyme, R233-01). Vazyme-ChamQ SYBY Color qPCR Master Mix (Vazyme, Q411-02) were used for qPCR. Gene-specific primers were listed in Additional file 15: Table S9. Relative gene expression level was calculated using actin as the internal control. Three biological replicates were prepared for each time point.

\section{RNA-seq data analysis}

High quality RNAs were submitted for mRNA sequencing library preparation and $150 \mathrm{bp}$ paired-end sequencing on Hiseq X 10 platform (Illumina). Clean sequencing reads were mapped to $P$. trichocarpa v3.0 genome assembly using hisat2 $[62,63]$ with default parameters. The raw mapped reads for each sample were counted using htseqcount [64]. The edgeR package [65] was used to identify significantly differentially expressed genes (DEGs), with Fisher's exact test false discovery rate (FDR) less than 0.05 as the statistical significance threshold.

\section{Gene co-expression network analysis}

The gene expression abundance was calculated and used for weighted gene co-expression network analysis (WGCNA) [66]. The soft threshold power of the adjacency matrix for co-expression relationship between genes is 12 . Hierarchical clustering was executed with a minimum module size of 300 and a cut height of 0.994 . The different modules were assigned to different colors. The Weighted Correlation Network Analysis (WGCNA) included method testing the correlation between co-expression module and sample traits. The gene expression matrix of the module was computed by PCA (Principal Components Analysis) to determine the PC1, Module Eigengene (ME), which represents the module. Then, the module-trait correlation was computed using all module MEs and trait data. $P$ value $<0.05$ was used as the statistical significance threshold. The co-expression network 
was analyzed using Cytoscape [67]. Transcription factor (TF) database is derived from Plant TFDB (http:// planttfdb.cbi.pku.edu.cn/index.php?sp=Ptr) [68].

\section{Gene ontology (GO) enrichment analysis}

P.trichocarpa v3 Gene ontology (GO) annotation was used, and the GO enrichment was analyzed using GOstats and GSEABase packages [69] with $P$-value $<0.01$. REVIGO [70] was used for visualization of enriched GO terms with default parameters.

\section{Additional files}

Additional file 1: Figure S1. Whole plant responses along the timecourse of $\mathrm{NaCl}$ treatments. a, plants with no salt treatment; b, plants treated with $100 \mathrm{mM} \mathrm{NaCl}$; c, plants treated with $100 \mathrm{mM} \mathrm{NaCl}$ followed with 3 days recovery, and then treated with $200 \mathrm{mM} \mathrm{NaCl}$; d, plants treated with $200 \mathrm{mM} \mathrm{NaCl}$ directly. Photos were taken at the time points indicated on the left side. (JPG $17970 \mathrm{~kb}$ )

Additional file 2: Figure S2. Gene cluster dendrogram based on the time-course RNA-seq data. (TIF $4128 \mathrm{~kb}$ )

Additional file 3: Figure S3. Enriched biological pathway (BP) in green module. (PNG $206 \mathrm{~kb}$ )

Additional file 4: Figure S4. Enriched biological pathway (BP) in turquoise module. (PNG $255 \mathrm{~kb}$ )

Additional file 5: Figure S5. Enriched biological pathway (BP) in blue module. (PNG $301 \mathrm{~kb}$ )

Additional file 6: Figure S6. Expression profile of representative genes from green (a), turquoise (b), and blue (c) module with RNA-seq data. (PDF $291 \mathrm{~kb}$ )

Additional file 7: Table S1. Summary of sequencing data. (XLSX $12 \mathrm{~kb}$ )

Additional file 8: Table S2. Summary of DEGs between individual time point and the corresponding control samples identified by edgeR analysis. (XLSX $9 \mathrm{~kb})$

Additional file 9: Table S3. DEGs between individual time point and the corresponding control samples identified by edgeR analysis. (XLSX $18432 \mathrm{~kb}$ )

Additional file 10: Table S4. Summary of co-expression modules derived from WGCNA analysis. (XLSX $9753 \mathrm{~kb}$ )

Additional file 11: Table S5. TF genes in all WGCNA modules. (XLSX $770 \mathrm{~kb}$ )

Additional file 12: Table S6. Summary of TF families in green, turquoise, and blue modules. (XLSX $11 \mathrm{~kb}$ )

Additional file 13: Table S7. Enriched GO terms of all modules. (XLSX $2113 \mathrm{~kb}$ )

Additional file 14: Table S8. Top 20 genes co-expressed with WOX4b and CLE41a from our RNA-seq data. (XLSX $11 \mathrm{~kb}$ )

Additional file 15: Table S9. Primers used for qPCR. (XLSX $11 \mathrm{~kb})$

\section{Abbreviations}

ABA: Abscisic acid; BP: Biological pathway; BR: Brassinosteroid; CC: Cellular component; CK1: Control samples of the first salt treatment; CK2: Control samples of the second salt treatment; DEGs: Differentially expressed genes; ET: Ethylene; GA: Gibberellins; GO: Gene Ontology; H1/H3/H6/H12: 1/3/6/12 h of salt treatment; JA: Jasmonic acid; MF: Molecular function; RNA-seq: RNA sequencing; RWC: Relative water content; SA: Salicylic acid; T1: The first salt treatment; T2: The second salt treatment; TF: Transcription factor; WGCNA: Weighted gene correlation network analysis

\section{Acknowledgements}

We thank Prof. Jiu-Hai Zhao for providing the computational server and data analysis pipeline, and Prof. Qing-Hua Shi for suggestions on the liquid culture of Populus. We thank Prof. Li liu for valuable discussions and comments.

\section{Authors' contributions}

$L L, A W$ and $X H$ conceived and designed the experiments. JL, TY and WC carried out the experiments and raw data generation. $\mathrm{XH}$ analyzed the data. $L L, J L$ and $X H$ wrote the manuscript, $C F$ and BW revised the manuscript. All authors read and approved the final manuscript.

\section{Funding}

This work was supported by National Natural Science Foundation of China to Li-Jun Liu (grant no. 31700583) and open funding from Guangdong Key Laboratory for Innovative Development and Utilization of Forest Plant Germplasm of South China Agricultural University to Li-Jun Liu. The funding bodies had no role in the design of the study and no role in the collection, analysis, and interpretation of data or in writing the manuscript.

\section{Availability of data and materials}

The raw sequence data reported in this paper have been deposited in the Genome Sequence Archive in BIG Data Center [71, 72] Beijing institute of Genomics (BIG), Chinese Academy of Science, under accession number CRA001067 that are publicly accessible at http://bigd.big.ac.cn/gsa.

Ethics approval and consent to participate

Not applicable.

\section{Consent for publication}

Not applicable.

\section{Competing interests}

The authors declare that they have no competing interests.

\section{Author details}

${ }^{1}$ State Forestry and Grassland Administration Key Laboratory of Silviculture in downstream areas of the Yellow River, College of Forestry, Shandong Agriculture University, Taian 271018, Shandong, China. ${ }^{2}$ State Key Laboratory of Subtropical Silviculture, College of Forestry and Biotechnology, Zhejiang A\&F University, Lin'an, Hangzhou 311300, China. 'Guangdong Key Laboratory for Innovative Development and Utilization of Forest Plant Germplasm, College of Forestry and Landscape Architecture, South China Agricultural University, Guangzhou 510642, China. ${ }^{4}$ Key Laboratory of Biofuels, Qingdao Engineering Research Center of Biomass Resources and Environment, Qingdao Institute of Bioenergy and Bioprocess Technology, Chinese Academy of Sciences, Qingdao 266101, Shandong, China. ${ }^{5}$ Photosynthesis Research Center, Key Laboratory of Photobiology, Institute of Botany, Chinese Academy of Sciences, Beijing 100093, China.

Received: 31 March 2019 Accepted: 29 July 2019

Published online: 20 August 2019

\section{References}

1. Jansson S, Douglas CJ. Populus: a model system for plant biology. Annu Rev Plant Biol. 2007;58:435-58.

2. Tuskan GA, Difazio S, Jansson S, Bohlmann J, Grigoriev I, Hellsten U, Putnam N, Ralph S, Rombauts S, Salamov A, et al. The genome of black cottonwood, Populus trichocarpa (Torr. \& Gray). Science. 2006;313(5793):1596-604.

3. Virlouvet L, Avenson TJ, Du Q, Zhang C, Liu N, Fromm M, Avramova Z, Russo SE. Dehydration stress memory: gene networks linked to physiological responses during repeated stresses of Zea mays. Front Plant Sci. 2018;9:1058.

4. Hilker M, Schwachtje J, Baier M, Balazadeh S, Baurle I, Geiselhardt S, Hincha DK, Kunze R, Mueller-Roeber B, Rillig MC, et al. Priming and memory of stress responses in organisms lacking a nervous system. Biol Rev Camb Philos Soc. 2016;91(4):1118-33.

5. Avramova Z. Transcriptional 'memory' of a stress: transient chromatin and memory (epigenetic) marks at stress-response genes. Plant J. 2015;83(1):149-59.

6. Arnholdt-Schmitt B. Stress-induced cell reprogramming. A role for global genome regulation? Plant Physiol. 2004;136(1):2579-86. 
7. Molinier J, Ries G, Zipfel C, Hohn B. Transgeneration memory of stress in plants. Nature. 2006;442(7106):1046-9.

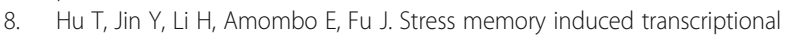
and metabolic changes of perennial ryegrass (Lolium perenne) in response to salt stress. Physiol Plant. 2016;156(1):54-69.

9. Ding Y, Fromm M, Avramova Z. Multiple exposures to drought 'train' transcriptional responses in Arabidopsis. Nat Commun. 2012;3:740.

10. Ding Y, Virlouvet L, Liu N, Riethoven JJ, Fromm M, Avramova Z. Dehydration stress memory genes of Zea mays; comparison with Arabidopsis thaliana. BMC Plant Biol. 2014;14:141.

11. Virlouvet L, Fromm M. Physiological and transcriptional memory in guard cells during repetitive dehydration stress. New Phytol. 2015;205(2):596-607.

12. Ding Y, Liu N, Virlouvet L, Riethoven JJ, Fromm M, Avramova Z. Four distinct types of dehydration stress memory genes in Arabidopsis thaliana. BMC Plant Biol. 2013;13:229.

13. Zhang C, Peng X, Guo X, Tang G, Sun F, Liu S, Xi Y. Transcriptional and physiological data reveal the dehydration memory behavior in switchgrass (Panicum virgatum L.). Biotechnol Biofuels. 2018;11:91.

14. Bar-Joseph Z, Gitter A, Simon I. Studying and modelling dynamic biological processes using time-series gene expression data. Nat Rev Genet. 2012;13(8):552-64.

15. Zinkgraf M, Gerttula S, Zhao S, Filkov V, Groover A. Transcriptional and temporal response of Populus stems to gravi-stimulation. J Integr Plant Biol. 2018;60(7):578-90

16. Lin YC, Li W, Sun YH, Kumari S, Wei H, Li Q, Tunlaya-Anukit S, Sederoff RR, Chiang VL. SND1 transcription factor-directed quantitative functional hierarchical genetic regulatory network in wood formation in Populus trichocarpa. Plant Cell. 2013;25(11):4324-41.

17. Gerttula S, Zinkgraf M, Muday GK, Lewis DR, Ibatullin FM, Brumer H, Hart F, Mansfield SD, Filkov V, Groover A. Transcriptional and hormonal regulation of gravitropism of woody stems in Populus. Plant Cell. 2015;27(10):2800-13.

18. Klepikova AV, Logacheva MD, Dmitriev SE, Penin AA. RNA-seq analysis of an apical meristem time series reveals a critical point in Arabidopsis thaliana flower initiation. BMC Genomics. 2015;16:466.

19. Sircar S, Parekh N, Sablok G. Protocol for Coexpression network construction and stress-responsive expression analysis in Brachypodium. Methods Mol Biol. 2018;1667:203-21

20. Bassel GW, Lan H, Glaab E, Gibbs DJ, Gerjets T, Krasnogor N, Bonner AJ, Holdsworth MJ, Provart NJ. Genome-wide network model capturing seed germination reveals coordinated regulation of plant cellular phase transitions. Proc Natl Acad Sci U S A. 2011;108(23):9709-14.

21. Sircar $S$, Parekh N. Functional characterization of drought-responsive modules and genes in Oryza sativa: a network-based approach. Front Genet. 2015;6:256.

22. Zinkgraf M, Liu L, Groover A, Filkov V. Identifying gene coexpression networks underlying the dynamic regulation of wood-forming tissues in Populus under diverse environmental conditions. New Phytol. 2017;214(4):1464-78.

23. Liu L, Ramsay T, Zinkgraf M, Sundell D, Street NR, Filkov V, Groover A. A resource for characterizing genome-wide binding and putative target genes of transcription factors expressed during secondary growth and wood formation in Populus. Plant J. 2015;82(5):887-98.

24. Chen J, Zhang J, Hu J, Xiong W, Du C, Lu M. Integrated regulatory network reveals the early salt tolerance mechanism of Populus euphratica. Sci Rep. 2017;7(1):6769

25. Yu L, Ma J, Niu Z, Bai X, Lei W, Shao X, Chen N, Zhou F, Wan D. TissueSpecific Transcriptome Analysis Reveals Multiple Responses to Salt Stress in Populus euphratica Seedlings. Genes (Basel). 2017;8(12):372.

26. Zhu JK. Salt and drought stress signal transduction in plants. Annu Rev Plant Biol. 2002:53(1):247-73.

27. Zhu Q, Zhang J, Gao X, Tong J, Xiao L, Li W, Zhang H. The Arabidopsis AP2/ ERF transcription factor RAP2.6 participates in ABA, salt and osmotic stress responses. Gene. 2010;457(1-2):1-12.

28. Yang O, Popova OV, Suthoff U, Luking I, Dietz KJ, Golldack D. The Arabidopsis basic leucine zipper transcription factor AtbZIP24 regulates complex transcriptional networks involved in abiotic stress resistance. Gene. 2009;436(1-2):45-55.

29. Cheng MC, Liao PM, Kuo WW, Lin TP. The Arabidopsis ETHYLENE RESPONSE FACTOR1 regulates abiotic stress-responsive gene expression by binding to different cis-acting elements in response to different stress signals. Plant Physiol. 2013;162(3):1566-82.

30. Lippold F, Sanchez DH, Musialak M, Schlereth A, Scheible WR, Hincha DK, Udvardi MK. AtMyb41 regulates transcriptional and metabolic responses to osmotic stress in Arabidopsis. Plant Physiol. 2009;149(4):1761-72.
31. Fang Y, Xie K, Xiong L. Conserved miR164-targeted NAC genes negatively regulate drought resistance in rice. J Exp Bot. 2014;65(8):2119-35.

32. Jiang Y, Deyholos MK. Functional characterization of Arabidopsis NaClinducible WRKY25 and WRKY33 transcription factors in abiotic stresses. Plant Mol Biol. 2009;69(1-2):91-105.

33. Jiang Y, Yang B, Deyholos MK. Functional characterization of the Arabidopsis bHLH92 transcription factor in abiotic stress. Mol Gen Genomics. 2009;282(5):503-16.

34. Etchells JP, Turner SR. The PXY-CLE41 receptor ligand pair defines a multifunctional pathway that controls the rate and orientation of vascular cell division. Development. 2010;137(5):767-74.

35. Kucukoglu M, Nilsson J, Zheng B, Chaabouni S, Nilsson O. WUSCHEL-RELATED HOMEOBOX4 (WOX4)-like genes regulate cambial cell division activity and secondary growth in Populus trees. New Phytol. 2017;215(2):642-57.

36. Golldack D, Luking I, Yang O. Plant tolerance to drought and salinity: stress regulating transcription factors and their functional significance in the cellular transcriptional network. Plant Cell Rep. 2011;30(8):1383-91.

37. Kim JM, Sasaki T, Ueda M, Sako K, Seki M. Chromatin changes in response to drought, salinity, heat, and cold stresses in plants. Front Plant Sci. 2015;6:114.

38. Lu X, Zhang X, Duan H, Lian C, Liu C, Yin W, Xia X. Three stress-responsive NAC transcription factors from Populus euphratica differentially regulate salt and drought tolerance in transgenic plants. Physiol Plant. 2018;162(1):73-97.

39. Hsieh TH, Li CW, Su RC, Cheng CP, Sanjaya, Tsai YC, Chan MT. A tomato bZIP transcription factor, SIAREB, is involved in water deficit and salt stress response. Planta. 2010;231(6):1459-73.

40. Liu J, Ishitani M, Halfter U, Kim CS, Zhu JK. The Arabidopsis thaliana SOS2 gene encodes a protein kinase that is required for salt tolerance. Proc Natl Acad Sci. 2000;97(7):3730-4.

41. Xiong L, Schumaker KS, Zhu JK. Cell signaling during cold, drought, and salt stress. Plant Cell. 2002;14(Suppl):S165-83.

42. Quintero FJ, Martinez-Atienza J, Villalta I, Jiang X, Kim WY, Ali Z, Fujii H, Mendoza I, Yun DJ, Zhu JK, et al. Activation of the plasma membrane $\mathrm{Na} / \mathrm{H}$ antiporter salt-overly-sensitive 1 (SOS1) by phosphorylation of an autoinhibitory C-terminal domain. Proc Natl Acad Sci U S A. 2011;108(6):2611-6.

43. Martinez-Atienza J, Jiang X, Garciadeblas B, Mendoza I, Zhu JK, Pardo JM, Quintero FJ. Conservation of the salt overly sensitive pathway in rice. Plant Physiol. 2007;143(2):1001-12.

44. Olias R, Eljakaoui Z, Li J, De Morales PA, Marin-Manzano MC, Pardo JM, Belver A. The plasma membrane $\mathrm{Na}+/ \mathrm{H}+$ antiporter SOS1 is essential for salt tolerance in tomato and affects the partitioning of $\mathrm{Na}+$ between plant organs. Plant Cell Environ. 2009;32(7):904-16.

45. Tang RJ, Liu H, Bao Y, Lv QD, Yang L, Zhang HX. The woody plant poplar has a functionally conserved salt overly sensitive pathway in response to salinity stress. Plant Mol Biol. 2010;74(4-5):367-80.

46. Gaxiola RA, Li J, Undurraga S, Dang LM, Allen GJ, Alper SL, Fink GR. Drought- and salt-tolerant plants result from overexpression of the AVP1 H+-pump. Proc Natl Acad Sci U S A. 2001;98(20):11444-9.

47. Yang $Y$, Tang RJ, Li B, Wang HH, Jin YL, Jiang CM, Bao Y, Su HY, Zhao N, Ma XJ, et al. Overexpression of a Populus trichocarpa H+-pyrophosphatase gene PtVP1. 1 confers salt tolerance on transgenic poplar. Tree Physiol. 2015;35(6):663-77.

48. Mehrotra R, Bhalothia P, Bansal P, Basantani MK, Bharti V, Mehrotra S. Abscisic acid and abiotic stress tolerance - different tiers of regulation. J Plant Physiol. 2014;171(7):486-96.

49. Verma V, Ravindran P, Kumar PP. Plant hormone-mediated regulation of stress responses. BMC Plant Biol. 2016;16:86.

50. Unterholzner SJ, Rozhon W, Papacek M, Ciomas J, Lange T, Kugler KG, Mayer $\mathrm{KF}$, Sieberer T, Poppenberger B. Brassinosteroids are master regulators of gibberellin biosynthesis in Arabidopsis. Plant Cell. 2015;27(8):2261-72.

51. Ren $G$, Li L, Huang Y, Wang Y, Zhang W, Zheng R, Zhong C, Wang X. GhWIP2, a WIP zinc finger protein, suppresses cell expansion in Gerbera hybrida by mediating crosstalk between gibberellin, abscisic acid, and auxin. New Phytol. 2018;219(2):728-42.

52. Silva NCQ, de Souza GA, Pimenta TM, Brito FAL, Picoli EAT, Zsogon A, Ribeiro DM. Salt stress inhibits germination of Stylosanthes humilis seeds through abscisic acid accumulation and associated changes in ethylene production. Plant Physiol Biochem. 2018;130:399-407.

53. Colebrook EH, Thomas SG, Phillips AL, Hedden P. The role of gibberellin signalling in plant responses to abiotic stress. J Exp Biol. 2014;217(Pt 1):67-75.

54. Virlouvet L, Ding Y, Fujii H, Avramova Z, Fromm M. ABA signaling is necessary but not sufficient for RD29B transcriptional memory during successive dehydration stresses in Arabidopsis thaliana. Plant J. 2014;79(1):150-61. 
55. D'Urso A, Brickner JH. Epigenetic transcriptional memory. Curr Genet. 2017; 63(3):435-9.

56. Chinnusamy V, Zhu JK. Epigenetic regulation of stress responses in plants. Curr Opin Plant Biol. 2009;12(2):133-9.

57. Granot G, Sikron-Persi N, Gaspan O, Florentin A, Talwara S, Paul LK, Morgenstern Y, Granot Y, Grafi G. Histone modifications associated with drought tolerance in the desert plant Zygophyllum dumosum Boiss. Planta. 2009:231(1):27-34.

58. Sani E, Herzyk P, Perrella G, Colot V, Amtmann A. Hyperosmotic priming of Arabidopsis seedlings establishes a long-term somatic memory accompanied by specific changes of the epigenome. Genome Biol. 2013;14(6):R59.

59. Liu N, Fromm M, Avramova Z. H3K27me3 and H3K4me3 chromatin environment at super-induced dehydration stress memory genes of Arabidopsis thaliana. Mol Plant. 2014;7(3):502-13.

60. Kim JM, To TK, Ishida J, Matsui A, Kimura H, Seki M. Transition of chromatin status during the process of recovery from drought stress in Arabidopsis thaliana. Plant Cell Physiol. 2012:53(5):847-56.

61. Wibowo A, Becker C, Marconi G, Durr J, Price J, Hagmann J, Papareddy R, Putra $\mathrm{H}$, Kageyama J, Becker J, et al. Hyperosmotic stress memory in Arabidopsis is mediated by distinct epigenetically labile sites in the genome and is restricted in the male germline by DNA glycosylase activity. Elife. 2016;5.

62. Pertea M, Kim D, Pertea GM, Leek JT, Salzberg SL. Transcript-level expression analysis of RNA-seq experiments with HISAT, StringTie and Ballgown. Nat Protoc. 2016;11(9):1650-67.

63. Kim D, Langmead B, Salzberg SL. HISAT: a fast spliced aligner with low memory requirements. Nat Methods. 2015:12(4):357-60.

64. Anders S, Pyl PT, Huber W. HTSeq--a Python framework to work with highthroughput sequencing data. Bioinformatics. 2015;31(2):166-9.

65. Wibowo A, Becker C, Marconi G, Durr J, Price J, Hagmann J, Papareddy R, Putra H, Kageyama J, Becker J, et al. Hyperosmotic stress memory in Arabidopsis is mediated by distinct epigenetically labile sites in the genome and is restricted in the male germline by DNA glycosylase activity. Elife 2016;5:e13546.

66. Langfelder P, Horvath S. WGCNA: an R package for weighted correlation network analysis. BMC Bioinf. 2008:9:559.

67. Shannon P, Markiel A, Ozier O, Baliga NS, Wang JT, Ramage D, Amin N, Schwikowski B, Ideker T. Cytoscape: a software environment for integrated models of biomolecular interaction networks. Genome Res. 2003;13(11):2498-504.

68. Jin J, Tian F, Yang DC, Meng YQ, Kong L, Luo J, Gao G. PlantTFDB 4.0: toward a central hub for transcription factors and regulatory interactions in plants. Nucleic Acids Res. 2017;45(D1):D1040-5.

69. Falcon S, Gentleman R. Using GOstats to test gene lists for GO term association. Bioinformatics. 2007;23(2):257-8.

70. Supek F, Bosnjak M, Skunca N, Smuc T. REVIGO summarizes and visualizes long lists of gene ontology terms. PLoS One. 2011;6(7):e21800.

71. Wang Y, Song F, Zhu J, Zhang S, Yang Y, Chen T, Tang B, Dong L, Ding N, Zhang Q, et al. GSA: genome sequence archive. Genomics Proteomics Bioinformatics. 2017:15(1):14-8.

72. BIG Data Center Members: Database Resources of the BIG Data Center in 2018. Nucleic acids research. 2018;46(D1):D14-D20.

\section{Publisher's Note}

Springer Nature remains neutral with regard to jurisdictional claims in published maps and institutional affiliations.

Ready to submit your research? Choose BMC and benefit from:
- fast, convenient online submission
- thorough peer review by experienced researchers in your field
- rapid publication on acceptance
- support for research data, including large and complex data types
- gold Open Access which fosters wider collaboration and increased citations
- maximum visibility for your research: over 100M website views per year
At BMC, research is always in progress.
Learn more biomedcentral.com/submissions

